\title{
An Analysis of Emissions Reduction Phenomenon in South Africa
}

\author{
Kola O. Odeku \\ Faculty of Management and Law, University of Limpopo, Turfloop, South Africa
}

Doi:10.5901/mjss.2014.v5n23p2709

\begin{abstract}
Climate change and global warming impacts are manifesting on a daily basis all over the world. Reports of catastrophic weather events are always being aired in the news, showing huge and massive destruction to property and life. Carbon emissions by both industrialised and non-industrialised countries are the main causes of global warming and climate change. While the developed nations are making frantic efforts through innovations and technologies to adapt to the changes in the climate, the developing countries do not have the capacity to develop such technologies, hence unable to adapt to the changes, leaving them with mitigation options. Against this backdrop, South African Government has put in place various interventions to curb the surge of global climate change. However, it is pertinent to point out that till date, there is no single law passed by the parliament specifically on global climate change. This notwithstanding, in view of the fact that global climate change is caused by emissions of harmful gases to the atmosphere and the environment, South Africa has ample laws controlling and regulating the environment. Therefore, the paper seeks to advance a compelling argument on implementation and enforcement of policy and law on carbon emissions reduction and how the law can be strengthened as part of mitigation strategy. As the issues surrounding global climate change relate and strictly pertain to the environment, the relevant environmental laws that are in place could be used to control and reduce emissions of all sorts and also enforce compliance. One of such pieces of legislation is the National Environmental Management: Air Quality Act 39 of 2004.
\end{abstract}

Keywords: Emissions reduction, Environment, Enforcement, National Environmental Management: Air Quality Act 39 of 2004

\section{Introduction}

The issues surrounding global climate change and sustainable development are increasingly becoming trans-disciplinary in nature (Najam et al, 2003). It is generally accepted that emissions of noxious gasses, as a result of human activities are causing global warming and climate change (Jorgenson, 2006). Prominent among them is the emission of carbon dioxide to the atmosphere. Scholars from different disciplines have researched extensively and presented their findings on how best to reduce or curb the devastating and unbearable heat caused by emissions (Christianson, 1999). In the same vein, governments around the world have persistently been coming up with various initiatives including laws on how best to bring down the 'heat' without compromising the delivery of socio-economic goods, amenities and services to the people (Hall, 2013). Law, as a discipline plays, and will continue to play a significant role in regulating human activities resulting in emissions of harmful gases to the atmosphere which is causing global climate change through the implementation and enforcement of laws on emissions reduction (Hester and Harrison, 2002).

South Africa is a Non-Annex I country party to the United Nations Framework Convention on Climate Change (UNFCCC). It is party to the Kyoto Protocol 1997, which means that the country is not under any international obligation to reduce its greenhouse gas emissions (Mumma and Hodas 2007). South Africa has however volunteered to reduce its greenhouse gas emissions by $34 \%$ below a business as usual emissions growth by 2020 (business as usual is the baseline which assumes that future development trends follow those of the past and no changes in policies will take place), and a 42\% reduction by 2025 (Newmarch 2013). This target is achievable if the country is able to receive appropriate finance, technology and capacity building support from developed countries. The country, has on its own, launched various initiatives and strategies to achieve this locally and assistance from the developed countries will thus compliment these local initiatives.

Furthermore, in its bid to commit to continue emissions reduction, the country has put in place various policy processes, the most recent of which is the National Climate Change Response Policy (October 2011) (National Policy), (Winkler and Marquand 2009). The National Policy is the latest in a number of milestones in climate change policy development, which include but not limited to; National Climate Change Response Strategy (September 2004), Long Term Mitigation Strategy Scenarios of 2006 and beyond, African National Congress (ANC) Polokwane Summit of December 2007, South African Climate Change Policy Summit of March 2009, Green Economy Summit of May 2010 and 
National Climate Change Response Green Paper of November 2010).

Driven by the concepts and principles of sustainable development, South Africa has voluntarily decided to take all measures to reduce its carbon footprints (Winkler and Spalding-Fecher, 2002). The recent promulgation of the National Environmental Management: Air Quality Act 39 of 2004 (NEMAQ) in particular and other related laws and policies are perfect testimonies to what the country is doing as part of a member of the international community to control, retard and stop the surge of global climate change (Fischer, 2009).

The focus of this paper is, through the use of legal lexicons, to find solutions to the problem of severe and bizarre weather events threatening human existence which are caused by human activities through the burning of fossil fuels. The law is a powerful tool that could be used as a catalyst for ensuring practical implementation and enforcement of carbon emissions reduction (Yang, 2008). Theoretically, in South Africa, there is dearth of statutory legislation on emissions reduction, but there is a paucity of personnel with the capacity to implement and enforce the law. As a result of this capacity gap, perpetrators are usually not sanctioned, thereby promoting a culture of impunity.

The concern is that developing countries of the world are the hardest hit and affected (Odeku and Meyer, 2010). Currently, there are various manifestations of weather catastrophes destroying both properties and human beings on the African continent (Kondratyev et al. 2006). The situation is exacerbated by the fact that African countries are the most vulnerable because of lack of adaptive and mitigation capacity to global climate change (Chhibber and 2008). South Africa, a developing country, is vulnerable due to its massive and intensive use of cheap coal to generate power for its energy intensive industrial activities (Winkler and Marquand, 2009). Coal is fossil fuel, it emits carbon dioxide that contributes to and causing global climate change (Ramanathan and Carmichael, 2008). This study seeks to present and articulate, in clear terms, the need to reduce emission using the might of the laws. It is pertinent to point out that it is feasible to control emissions and at the same time responsibly grow the economy and deliver sustainable social economics goods and services to the people (Banerjee, 2008).

This paper, therefore, reviews the broad approaches taken for the purpose of carbon emissions reduction, through implementation and enforcement of NEMAQ in particular and other related laws and policies to address the issues surrounding the hazards of carbon dioxide emissions in order to gradually reduce and eventually stop emissions. (Jorgensen and Siegel, 2009).

\section{Rationale behind the Study}

Climate change is threatening human existence and ecosystems ( Stern, 2007). The manifestation of climate catastrophe is a major concern to everybody and as such, to tackle the surge, it requires collective responsibility and action (Harris, 2009). The United Nations has enjoined all governments of the world, to take steps to curb the surge of climate change and global warming through various means, hence the importance of using laws to control and enforce emissions reduction (Meyer and Odeku, 2009). Even though, the developed countries are the 'global warming-perpetrators' by their massive burning of fossil fuels during the periods of industrial revolutions, the developing countries are enjoined not to follow this unsustainable developmental paths (Meadowcroft, 2007). Consequent upon this, while the developing countries are encouraged to grow their economy in order to deliver socio economic goods and services, it is expected that this should be done reasonably and sustainably (Rodrik, 2008). Against this backdrop, caution and self-restraint are needed in order to control developmental activities that will aggravate the problem (Chambers, 2005). Toward this end, there should be close monitoring, control, implementation and enforcement of all interventions that will prevent emissions. The potent tools to achieve these are numerous interventions and laws that have been put in place or are being implemented and enforced. The application and enforcement of these interventions will discourage and prevent developing countries from replicating what the developed countries have been accused of doing for the past 200 years (Sovacool, 2014). More importantly, there is need for developing countries to ensure holistic interventions in emissions reduction because they are vulnerable and do not have capacity to adapt (Yamin et al. 2005). It is therefore argued that sanctions and punishments contained in different carbon emissions laws, if enforced, will make possible gradual transition to emissions reduction. Pursuant to this, penalties in section 52 of the NEMAQ become potent mechanisms to compel and enforce emissions reduction.

The paper seeks to promote and ensure an environment that is not harmful to the well-being of the people and to protect the environment for the benefit of the present and future generations (Doremus, 2004). The right to clean environment and sustainable development contained in Section 24 of the Constitution of the Republic of South Africa 1996 will become practicable and realisable through implementation and enforcement (Clemson, 2012). Section 24 of the Constitution also compels everyone to take reasonable steps to prevent pollution and ecological degradation, promote conservation and secure ecologically sustainable development and use of natural resources (Feris, 2010). Given the 
Constitutional imperatives, this study is viable and needs to be pursed vigorously as the findings will serve as an impetus to reduce carbon emissions making the world a better place to live (Steger et al. 2005). The overall benefit will be the achievement of the Outcome 10 vision of the Environmental Sector Plan vision which seeks to ensure: "a prosperous and equitable society living in harmony with our natural resources" (DEA, 2012). Pursuant to this, both natural and human resources are expected to provide and promote the common good for all in order to continue to sustain "a South Africa where environmental assets and natural resources are valued, protected and continually enhanced"( DEA, 2012).

The justification for this paper is that African continent is vulnerable to the impact of global climate change (Collier et al. 2008). The continent lacks both mitigation and adaptive strategies because of lack of capacities in technologies that could be used to implement these strategies (Twomlow et al. 2008). South Africa is the highest emitter of carbon dioxide on the African continent (Bombelli et al. 2005). It relies on the massive deposit of coal, which is being burnt and used to processed various industrial activities, and in the process emits harmful gases and carbon dioxide (Ramalope, 2014). Emissions from the coal are contributing to global warming causing climate change which is affecting virtually all sectors of South Africa including human beings (Roberts, 2008). If the emissions are not controlled or stopped, there could be catastrophic destruction of the country and its people (Lomborg et al. 2009). In order to avert this, the justification for aggressive steps to reduce emissions.

The paper contributes to the body of knowledge by improving understanding and generates new knowledge. It is also beneficial to a whole range of private and government institutions by providing a robustly enhanced understanding in the areas of successful possible sanctions and liabilities against perpetrators for failure to observe and comply with the laws on carbon emissions reduction.

\section{Gap in Knowledge and Problem Statement}

While research on environmental law and management is well documented in South Africa, the same cannot be said of the implementation and enforcement of carbon emissions using NEMAQ. Against this backdrop, there is paucity of scholarly information on how to implement and enforce the laws on carbon emissions and make perpetrators accountable by holding them civilly or criminally liable. This has thus created a huge lacuna. Consequently, a lot of climate culprits have escaped sanctions. In order to address culture of impunity, there should be administrative, political and judicial wills to enforce the laws on emissions reduction by bringing perpetrators to justice.

The concern is that, if nothing is done to control and stop emissions, the manifestations of the impacts of climate change may lead to unimaginable consequences (Glicksman, 2006). The paper seeks to dig deeper into various laws already put in place to curb carbon emissions by engaging in critical in-depth research analysis on how they can be practically implemented and enforced in order to attain the desired result of clean and sustainable planet for all generations.

\section{Research Aim and Objectives}

The aims and objectives are informed by the knowledge gap in carbon emissions reduction which tends to make perpetrators and polluters escape liability, thereby, promoting culture of impunity. Against the backdrop of this, the key aims and objectives that underpinned what the study sets out to achieve are articulated thus:

\subsection{Aim of the study}

To advance arguments for using the laws to compel emissions reduction in order to reduce and gradually abate devastating impacts and consequences of global warming and climate change. Towards this end, the likelihood of the scientific predictions of weather catastrophes as a result of global warming will be minimised. In order to achieve this, the study advances argument for drastic emissions reduction and curbing global climate change. More importantly, the study accentuates the need to bring polluters and climate culprits to book. Pursuant to this, South Africa will be seen to be 'walking the talk' as explicitly articulated in the various international and national instruments on emissions reduction.

\subsection{Objectives of the Study}

The key objective of the study is to examine the implementation and enforcement of laws on carbon emissions, and in particular NEMAQ, as panacea for curbing global climate change. 


\section{National Environmental Management: Air Quality Act 39 of 2004: An Overview}

The NEMAQ explicitly states the reasons and purposes for which it was promulgated thus "to reform the law regulating air quality in order to protect the environment by providing reasonable measures for the prevention of pollution and ecological degradation and for securing ecologically sustainable development while promoting justifiable economic and social development; to provide for national norms and standards regulating air quality monitoring, management and control by all spheres of government; for specific air quality measures; and for matters incidental thereto"( NEMAQ 2004).

Literature on global warming and climate change has confirmed that these unprecedented weather events are impacting the environment, (Jentsch et al. 2007) atmosphere and the planet earth (Richardson et al. 2011). If we continue on our present course, life on earth will be inextricably altered ( Dodds, 2008). To tackle and curb the surge, the relevant environmental laws that are in place are powerful mechanisms that can be used to control and reduce emissions of all sorts and also enforce compliance (Kettl, 2004). One of such pieces of legislation is the National Environmental Management: Air Quality Act 39 of 2004 which has an ambitious focus that seeks to

"a) to protect the environment by providing reasonable measures for-

(i) the protection and enhancement of the quality of air in the Republic;

(ii) the prevention of air pollution and ecological degradation; and

(iii) securing ecologically sustainable development while promoting justifiable economic and social development; and-

(b) generally to give effect to section 24(b) of the Constitution in order to enhance the quality of ambient air for the sake of securing an environment."

Undoubtedly, carbon emission is known to polluting and compromising air quality and it is also regarded as harmful substance because it is causing global climate change (Glicksman and Levy, 2008). This argument also goes for other greenhouse gases causing global climate change and degrading the environment. Therefore, NEMAQ is one of the potent Acts that is available to manage, control and protect the environment from pollution from carbon dioxide and other greenhouse gases.

The preamble to NEMAQ clearly highlights the dangers and hazards of air pollution and other environmental degradation and their consequences thus:

"WHEREAS the quality of ambient air in many areas of the Republic is not conducive to a healthy environment for the people living in those areas let alone promoting their social and economic advancement;

And whereas the burden of health impacts associated with polluted ambient air falls most heavily on the poor;

And whereas air pollution carries a high social, economic and environmental cost that is seldom borne by the polluter;

And whereas atmospheric emissions of ozone-depleting substances, greenhouse gases and other substances have deleterious effects on the environment both locally and globally."

It goes on to succinctly states the constitutionally guaranteed rights and entitlements and the need to preserve and protect them for both current and future generations thus:

"And whereas everyone has the constitutional right to an environment that is not harmful to their health or well-being; And whereas everyone has the constitutional right to have the environment protected, for the benefit of present and future generations, through reasonable legislative and other measures that-

(a) prevent pollution and ecological degradation;

(b) promote conservation; and

(c) secure ecologically sustainable development and use of natural resources

And whereas minimisation of pollution through vigorous control, cleaner technologies and cleaner production practices is key to ensuring that air quality is improved;

And whereas additional legislation is necessary to strengthen the Government's strategies for the protection of the environment and, more specifically, the enhancement of the quality of ambient air, in order to secure an environment that is not harmful to the health or well-being of people."

NEMAQ's categorically provides for responsibilities to protect and preserve the environment and apportions responsibilities to all spheres of government in this regard and resource persons to discharge those responsibilities. It stipulates measures and plans that should be strategically employed to achieve the set goals. More importantly, in section 21, it stipulates listing of activities resulting in atmospheric emissions and controlled mechanisms to degrade and curb emissions of all sorts. More importantly, it provides for penalties in section 51 . These penalties are to be meted out to anyone found guilty of activities that are harmful and injurious to the environment. Despite all these enforceable 
compliance and implementation mechanisms, polluters continue to thrive in their trades and the environment continues to be harmed because of lack of adequate enforcement.

Furthermore, with regard to implementation and enforcement challenges, it is hereby stressed that failure or inaction of the people who are given the responsibility to implement and enforce various instruments on carbon emissions reduction is the main reason for the continued increase in emissions with impunity by the perpetrators. Consequent upon this, the study emphasises the need for everyone to act responsibly and do what is right with appropriate measures taken against culprits both criminally and otherwise.

\section{Conclusion}

Carbon emissions reduction is ideal and noble and as such will have a positive impact on the society and humanity. To this end, appropriate stringent sanctions and measures need to be applied and enforced in order to tackle, degrade and curb global climate change.

\section{Recommendations}

There is a general consensus by the international community to pursue emissions reduction globally (Cooper, 2000). Virtually all disciplines are now being called in aid to achieve this. Law plays an important role in regulating and controlling all endeavours and as such, as part of the solution to reduce emissions harming and destroying the planet earth, stringent implementation and enforcement of the law will make a very useful contribution in addressing the surge of global climate change (Percival, 2003).

Moreover, global climate change phenomenon is a cross-cutting issue (Parmesan and Yohe, 2003); it is not peculiar to a particular country (Burton et al. 2006). Poor developing countries that do not have appropriate resilience are the hardest hit (Dodman et al. 2009). This is the reason why all hands should be put on the deck as the fight against carbon dioxide emissions should be the responsibility of everybody (Elshof, 2011). While research into emissions reduction is welcomed, more needs to be done in terms of applying and implementing solutions and outcomes of the research in practical terms (Audsley et al. 2010).

\section{References}

Audsley E, Brander M, Chatterton J C, Murphy-Bokern D WC, Williams A G 2010. How low can we go? An assessment of greenhouse gas emissions from the UK food system and the scope reduction by 2050. Report for the WWF and Food Climate Research Network. From https://dspace.lib.cranfield.ac.uk/handle/1826/6503. (Retrieved on November 29, 2013).

Banerjee SB 2008. Corporate social responsibility: The good, the bad and the ugly. Critical Sociology, 34(1): 51-79.

Barraclough SL 2005. In Quest of Sustainable Development. From http://scholar.google.co.za/scholar?hl=en\&q=+++barraclough +sl+2005.+in+quest+of+sustainable+development\%2c+overarching+concerns+paper+number+4+september+2005sdtp=. (Retrieved September 4, 2013).

Bombelli A, Henry M, Castaldi, S, Adu-Bredu S, Arneth A, de Grandcourt A, Grieco E, Kutsch W L, Lehsten V, Rasile A, Reichstein M, Tansey K, Weber U, Valentini R 2005. An outlook on the Sub-Saharan Africa carbon balance. Biogeosciences, 6:2193-2205.

Burns M, Audouin M, Weaver A. 2006. Advancing sustainability science in South Africa. South African Journal of Science, 102: $379-384$.

Burton I, Diringer E, Smith J 2006 . Adaptation to Climate Change: international policy options. From http://paccperu.org.pe/descargas/biblio/CC_2044.pdf. (Retrieved on March 23, 2013).

Chambers R 2005. Ideas for development, Earthscan Publishers, London, UK.

Chhibber A, Laajaj R 2008. Disasters, climate change and economic development in sub-Saharan Africa: lessons and directions. Journal of African Economies, 17(2):7-49.

Christianson G 1999. Greenhouse: the 200-year story of global warming, Walker publishing Company Incorporation, Vancouvers, Canada.

Clemson M 2012. Human Rights and the Environment: Access to Energy. New Zealand Environmental Law Journal, 16:39-51.

Collier P, Conway G, Venables T 2008. Climate change and Africa. Oxford Review of Economic Policy, 24 (2): 337-353.

Cooper RN 2000. International approaches to global climate change. The World Bank Research Observer, 15 (2): 145-172.

DEA 2012. Department of Environmental Affairs, South Africa. Environment Sector Research, Development and Evidence framework, An approach to enhance sector science-policy interface and evidence-based policy making. From https://www.environment.gov.za/sites/default/files/docs/environmental_research_framework.pdf. (Retrieved December 19, 2013).

DEA, 2009. Department of Environmental Affairs. Human Capital Development Strategy Environmental Sector A systems approach to skills development to support the Environmental Sector Strategic Plan 2009 - $2014 . \quad$ From https://www.environment.gov.za/sites/default/files/docs/human_capital_strategy_environmental_sector.pdf. (Retrieved November 22, 2013). 
Dodman D, Ayers J, Huq S 2009. Building resilience. From http://www.worldwatch.orgwww.worldwatch.org/files/pdf/SOW09_chap5.pdf. From (Retrieved on May 8, 2013).

Dodds WK 2008 . Humanity's footprint: momentum, impact, and our global environment. Fromhttp://books.google.co.za/books?hl =en\&lr=\&id=vyxgagaaqbaj\&oi=fnd\&pg=pr9\&dq=literature+on=lqhprebv7v\&sig=i4_vmpfguowaoidj3nw_v5rlx7a\#v=onepage\&q\&f=f alse. (Retrieved 11 October, 2014).

Doremus H 2004. Shaping the Future: The Dialectic of Law and Environmental Values. Environs: Environmental Law \& Policy Journal, 27: 233-244.

Elshof L 2011. Can education overcome climate change inactivism. Journal for Activism in Science \& Technology Education, 3(1):16-51.

Feris LA 2010. The role of good environmental governance in the sustainable development of South Africa. http://www.scielo.org.za/scielo.php?pid=S1727-37812010000100003\&script=sci_arttext\&tlng=es. (Retrieved on July 4, 2013).

Fischer D 2009. Environmental management co-operative agreements: a contribution to pollution prevention in South Africa. From https://ujdigispace.uj.ac.za/handle/10210/2009. (Retrieved on October 19, 2013).

Glicksman R L 2006. Global Climate Change and the Risks to Coastal Areas from Hurricanes and Rising Sea Levels: The Costs of Doing Nothing. Loyola Law Review, 52:1127-1136.

Glicksman R L, Levy R E 2008. Collective Action Perspective on Ceiling Preemption by Federal Environmental Regulation: The Case of Global Climate Change, North-western University Law Review, 102:579-586.

Harris PG 2009. Climate change in environmental foreign policy. Routledge, New York, South Africa.

Hall M 2013. Victims of Environmental Harm: Rights, Recognition and Redress Under National and International Law. New York, USA: Routledge.

Hester RE, Harrison RM 2002. Global environmental change, The Royal Society of Chemistry, Cambridge, UK.

Jentsch A, Kreyling J, Beierkuhnlein C 2007. A new generation of climate-change experiments: events, not trends. Frontiers in Ecology and the Environment 5: 365-374.

Jorgensen SL, Siegel PB 2009. Addressing human vulnerability to climate change: Toward a 'no-regrets' approach, Global Environmental Change, 19(1):89-99.

Jorgenson AK 2006. Global warming and the neglected greenhouse gas: A cross-national study of the social causes of methane emissions intensity. Social Forces, 84 (3): 1779-1798.

Kettl F 2004. Environmental governance: a report on the next generation of environmental policy. Brookings Institution, Washington, USA.

Kondratyev KY, Varotsos CA, Krapivin VF2006. Natural Disasters as Interactive Components of Global Ecodynamics. From http://link.springer.com/book/10.1007/3-540-37714-X. (Retrieved on December 14, 2013).

Lomborg B, Miller FP, Vandome AF, McBrewster J 2009. Skeptical environmentalist. From http://catdir.loc.gov/catdir/samples/cam031/00068915.pdf. (Retrieved on February 11, 2014).

Meadowcroft J 2007. National sustainable development strategies: features, challenges and reflexivity, Environmental Policy and Governance 17(3):152-163.

Meyer E, Odeku KO 2009. Climate Change, Energy and Sustainable Development in South Africa: Developing the African Continent at the Crossroads, Sustainable Development Law \& Policy Journal, American University Washington College of Law, 10(2):49-53.

Mumma A, Hodas D 2007. Designing a Global Post-Kyoto Climate Change Protocol that Advances Human Development, Georgia International Environmental Law Review, 20:619-629.

NEMAQ 2004. National Environment Management: Air Quality Act, 2004. From http://www.tshwane.gov.za/Services /EnvironmentalManagement/Environmental\%20Management\%20Documents/National\%20Air\%20Quality\%20Act.pdf. (Retrieved 16 October, 2014).

Najam A, Rahman AA, Huq S, Sokona Y 2003. Integrating sustainable development into the Fourth Assessment Report of the Intergovernmental Panel on Climate Change, Climate Policy, 3(1):7-17.

Newmarch J 2013.Does money grow on trees? : the role of climate change finance in South Africa. From http://wiredspace.wits.ac.za/handle/10539/13177. (Retrieved December 1, 2013).

Odeku K, Meyer E, 2010. Climate Change Surge: Implementing Stringent Mitigation and Adaptation Strategies in South Africa, Journal of African Law, Cambridge University Press, 54(2):159-183.

Parmesan C, Yohe G 2003. A globally coherent fingerprint of climate change impacts across natural systems. Nature, 421(2): 37-42.

Percival RV, Schroeder CH, Miller AS 2003. Environmental regulation. From http://www.law.uh.edu/faculty/thester/courses /environmental\%20law\%202013/psml\%20text/psml\%20chap\%201.pdf. (Retrieved on March 23, 2013).

Ramalope D 2014. Air pollution control measures implemented by the South African iron and steel industries. From https://152.106.6.200/handle/10210/9967. (Retrieved on August 3, 2014).

Ramanathan V, Carmichael G 2008. Global and regional climate changes due to black carbon. Nature Geoscience, Nature Geoscience 1: $221-227$

Ramanathan V, Carmichael G 2008. Global and regional climate changes due to black carbon, Nature Geoscience 1:221-227.

Richardson K, Steffen W, Liverman D 2011. Climate change: Global risks, challenges and decisions. Cambridge University Press, Cambridge, UK.

Roberts D 2008. Thinking globally, acting locally_institutionalizing climate change at the local government level in Durban, South Africa. Environment and Urbanization, 20 (2):521-537.

Rodrik D 2008. One economics, many recipes: globalization, institutions, and economic growth, Princeton University Press, New Jersey, 
USA.

Sovacool BK 2014. What are we doing here? Analyzing fifteen years of energy scholarship and proposing a social science research agenda. Energy Research \& Social Science, 1:1-29.

Steger U, Achterberg W, Blok K, Bode H, Frenz W, Gather C, Hanekamp G, Imboden D, Jahnke M, Kost M 2005. Sustainable Development and Innovation in the Energy Sector. From http://link.springer.com/book/10.1007/b138239. (Retrieved on June 14, 2013).

Stern N 2007. The economics of climate change: the Stern review. Cambridge University Press, Cambridge, UK.

Twomlow S, Mugabe FT, Mwale M, Delve R, Nanja D, Carberry P, Howden M 2008. Building adaptive capacity to cope with increasing vulnerability due to climatic change in Africa - A new approach. Physics and Chemistry of the Earth, 33(8-13):780-787.

Winkler H, Spalding-Fecher R 2002. sustainable development policies and measures. from http://www.erc.uct.ac.za/research/publications/05winkler-baumert_sdpams.pdf. (Retrieved on May 16, 2013).

Winkler H, Marquand A 2009. Changing development paths: From an energy-intensive to low-carbon economy in South Africa, Climate and Development, 1(1): 47-65.

Yamin F, Rahman A, Hug S 2005. Vulnerability, Adaptation and Climate Disasters: A Conceptual Overview, Institute of Development Studies (IDS) Bulletin, 36(4):1-14.

Yang T 2008. The Emergence of Global Environmental Law. From http://works.bepress.com/tseming_yang/1. (Retrieved September 19, 2013.

Zaelke D, Cameron J 1989. Global Warming and Climate Change-An Overview of the International Legal Process, American University Journal of International Law and Policy, 5:249-252. 